

\title{
Linking the subcultures of physics: Virtual empiricism and the bonding role of trust
}

\author{
Luis Reyes-Galindo
}

Cardiff University, School of Social Sciences, Cardiff, UK

\begin{abstract}
This article draws on empirical material concerning the communication and use of knowledge in experimental physics and their relations to the culture of theoretical physics. The role that trust plays in these interactions is used to create a model of social distance between interacting theoretical and experimental cultures. This article thus seeks to reintroduce trust as a fundamental element in answering the problem of disunity in the sociology of knowledge.
\end{abstract}

\section{Keywords}

physics, trust, enculturation, interactional expertise, disunity

Email: $\quad$ LuisReyes@ciencias.unam.mx (permanent) ReyesGalindoL@cf.ac.uk

Accepted for publication in Social Studies of Science, 17 May 2014.

Introduction: Knowledge transfer in fragmented sciences

Galison (2010) describes STS's emphasis on 'the locality of practice' as the result of a rich empirical tradition that has given rise to the so-called 'problem of disunity' (Galison, 1996b) - resolving how knowledge is transmitted between scientific fields despite deep linguistic and cultural fragmentation. ${ }^{1}$ Two well-known solutions to the problem of disunity are Galison's trading zones and Star and Griesemer's boundary objects (Galison, 1996a, 1997; Star and Griesemer, 1989), both characterized by the establishment of common and neutral linguistic spaces that coordinate action and distribute epistemic legitimacy between different knowledge cultures within highly heterogeneous interdisciplinary contexts (Galison, 1996a; Monteiro and Keating, 2009; Wilson and Herndl, 2007). In this paper I draw attention to a different understanding of the problem of disunity that does not rely on the need for 'multiple worlds organized ecologically around issues of mutual concern and commitment to action' (Clarke and Star, 2008) as a prerequisite for the communication of scientific knowledge. This will be done by analyzing the role of trust in allowing communication to occur in different physics communication settings.

The identification of different kinds of trust corresponding to different levels of interaction will be carried out in order to define a scale of 'social distance' in terms of knowledge practices between distinct cultural groups. Additionally, Collins and Evans' $(2002,2007)$ enculturation model will be introduced to make sense of interactions that are not typically thought to involve trust relationships 
directly. This 'enculturation model' hinges on cases of passive ingress of one cultural group into another's domain where the linguistic contact space lies inside the boundaries of one of the groups, with the other one then being 'parasitic' on it and is the stepping stone to evaluating communications settings that depart from the 'common ground' cooperative settings by Galison and Star and Griesmer.

This paper will first present interview material to illustrate the mechanisms underlying communication of experimental knowledge to theoretical physics across varying degrees of 'social distance', focusing on the social mechanisms that make these exchanges possible. Theoretical physics lends itself to this analysis because it is a highly heterogeneous field made up of various highly autonomous subcultures, some of which interact more directly than others with experimental cultures. 'Social distance' will then be related to the types of trust established between theoretical physicists and experimental cultures.

The paper's empirical material is taken from interviews with over twenty theoretical physics researchers at seven European universities and one in Latin America; these were part of a doctoral research project concerned with analyzing various elements of the practice of theoretical physics. The interviewees were chosen in order to cover the widest possible spectrum of theoretical sub-cultures of the theoretical physics community and except for one were all tenured full-time researchers at prestigious physics institutes or schools. The choice of interviewees was based on the author's close acquaintance with the culture of theoretical physics and convenience samplings stemming from his work as a research assistant and postdoctoral researcher in theoretical solid-state models of quantum vacuum forces for over ten years. The empirical study relied on a qualitative 'participant comprehension' approach which has been previously been used in canonical sociology of physics research (see Collins, 1984). The interviewees' main research topics are outlined in Table 1, divided between high (or pure) theory and theory of more 'applied' type: ${ }^{2}$

\begin{tabular}{|l|l|}
\hline High Theory & Phenomenology and modelling \\
\hline (H1) stochastic quantum mechanics, (H2) & (P1) applied quantum field theory \\
dark matter and energy, cosmology, & and acoustics, (P2) computational \\
condensed matter (H3) theoretical optics & nanophysics, (P3) computational \\
and applied mathematics, (H4) particle & nanophysics, (P4) computational \\
physics, quark models(H5) & quantum chromodynamics (QCD), \\
thermodynamics and statistical & (P5) gravitational wave experiment \\
mechanics, (H5) gravitational wave & analysis, (P5) optic experiment \\
theory, (H6) general relativity, (H7) & analysis, (P6) quantum \\
quantum computing and information & electrodynamics modelling, (P7) \\
theory, (H8) astrophysics, (H9) biophysics, & Bose-Einstein condensate \\
(H10) particle astrophysics and & modelling, (P8) computational \\
cosmology, (H11) theoretical optics. & particle physics. \\
\hline
\end{tabular}


The social gap between high-theory and experiment

Cultural and linguistic fragmentation through specialization occurs across all of science, but physics offers a particularly interesting case because of the very distinct division of labour that exists between theory and experiment - markedly different from, for example, some of the biological sciences where the division between theory and experiment is not seen to be a critical structuring factor of the field as a whole. ${ }^{3}$

The mathematically oriented, theoretical subculture that I will focus on in the first sections of this paper will be referred to as high-theory. High-theory is the kind activity most often thought to comprise 'theoretical physics', concentrating on posing, manipulating and finding solutions to the equations that govern the most basic interactions between physical bodies using highly mathematical language (and increasingly, computers). It is sometimes also referred to as 'pure' theoretical physics in opposition to 'applied' theory that deals with concrete physical systems. High-theory is often abstract, dealing with hypothetical physical universes, physically unrealized scenarios, etc. Some high-theoreticians are only a step away from doing applied mathematics, concentrating on problems that are only loosely tied to a physical interpretation of the mathematical techniques being used.

How far from an experimental physics culture is high-theory in its daily practice? Consider the following reply when a senior high-theoretician was asked about the relevance of experiment for his own work:

It is quite clear that nowadays you can do excellent theoretical physics without knowing how to even tighten a screw. A good theoretician can acquire profound and solid physical intuition while being completely detached from experiment.

Yet this same theoretician remarked only moments later:

For theory, experiment is a fundamental guide. Physics is still a science with an experimental foundation. One must always be aware of how the experimental results were arrived at. One must have a clear idea of the limitations of the experiments so that one can appreciate to what degree what one is doing is really well founded. Theoretical physicists aren't always aware of these details, but it is one of the main barriers you face in this field.

A simultaneous portrayal of theoretical physics as both fully detached but at the same time 'grounded' in experiment is often encountered when interviewing hightheoreticians about the role of experiment in their work. ${ }^{4}$ This rhetorical stance, which considers physical theory as an empirically based science, is common to theoretical discourse, even though members of high-theoretical cultures only rarely maintain direct contact with experiment. Some high-theoreticians may even devote entire portions of their professional lives to making novel and 'empirically testable' predictions of observable phenomena, yet never work directly with a lab. 
Thus a senior high-theoretician who has worked on optical phenomena throughout his career explained:

Reyes-Galindo: You've made quite a few theoretical predictions of phenomena. Do you have any direct contact with a laboratory where you can say, 'do this' or 'don't do this'?

Theoretician: No, no, no. In this conical refraction episode, astonishingly and actually for the first time - I had some contact with an experimental group in Dundee. I've just recently encountered them. I'm predicting all kinds of things, like if you put crystals in series what would you get, and so on. That's something where I'm directly involved, but it's unusual for me. I don't normally do that. There are different types of theorists, and some people work very close with the experimentalists. It's fun to do that, but I tend not to.

Full appropriation of laboratory knowledge can only happen through direct and prolonged engagement with an actual laboratory culture; without direct contact with an experimental culture high-theoreticians cannot 'have a clear idea of the limitations of the experiments' or 'appreciate to what degree what one is doing is really well founded'. ${ }^{5}$ So while few theoreticians would deny the impact of experiment on high-theoretical work, ${ }^{6}$ high-theory's minimal contact with experimental cultures indicates that if experiment is a guide for theoretical work it cannot be so through a simplistic sort of direct empiricism.

\section{You need a busload of faith to get by}

Elaborating on how the appropriation of experimental knowledge comes about in his own work, a young theoretician specializing in high-energy physics, superstring theory, gravity and other (as he described it) 'sexy' high theory subjects explained:

At some point I have to take on faith what experimenters tell me. I know that there are important questions that need to be answered like the cosmological constant, dark matter, the spectrum of Cosmic Microwave Background radiation or fluctuations you can see, problems in fractional quantum Hall effect or high temperature superconductivity. I've never done any of those experiments, and I don't understand most of the experiments, but you know, I have faith in these problems that need answering. [emphasis added]

Of course, the idea of faith as a foundational element of physical theory contradicts the typical views of physics as a directly empirical science. Yet high-theoreticians constantly refer to trust in explaining how experimental knowledge trickles down from the lab to the theoretician's blackboard or simulation - though not without some degree of resistance even for a candid interviewee such as the one above. When pressed to explain what this 'faith' implied, the same theoretician remarked that it was not so much a matter of 'blind faith' but rather of selecting who to 
believe, a kind of 'trust', since given enough time and resources he was sure that the experimental results on which he based his work would end up being verified:

I'd call it trust, but trust based on lots of evidence and trust that I can test it at any time. Certainly I don't understand the way LHC [Large Hadron Collider] works. But I could. I could sit down and spend three years of my life figuring this out. [emphasis added].

How realistic is the possibility of carrying out this fact-checking personally? When asked about the possibility that another theoretician might fully understand the LHC results he uses in his own work, the theoretician replied that although he could not name such a person on the spot, there certainly had to be theoreticians at CERN who would be able to understand these experiments:

I know theoreticians who understand it. I'm sure they didn't put a fuse together, but yeah, I know ... uh ... for example the ones who work at LHC full time, they could tell you what all the quirks were, what could be going wrong, what to worry about.

But for a high-theoretician to spend three years of his or her life understanding the intricacies of an LHC-like experiment would require spending three years away from practice as a high-theoretician. That a theoretician would have the intellectual capacity to fully understand an experiment, given enough time, is not in doubt, but the practical requirements of fact-checking the scientific output of an alien knowledge culture conflicts with the fact that this would lead him away from the professional high-theoretical world. As a theoretician who has turned to more applied work explained:

In my work I must make an effort, an enormous effort, to see if what I am saying has anything to do with what is out there, with an experiment. I think there are two kinds of theoreticians. I am of the pragmatic kind, although if you look at the everyday stuff I do it's just as abstract as the people who do mathematical physics. [laughs] ... The more I talk to them the deeper my knowledge about the experiment and the experimental result is. Nowadays I can actually see their naked experimental results without any analysis and know what it is they did, but that's as far as I can go. The part that I participate in the most is when I tell them, 'Look, why don't you try this new thing' and they'll reply something like, 'No, that's way too hard.' 'Why?' I'll ask. 'You can't do that to the coils.' 'Ah, ok.' Well, then you keep on talking. In general, the more you speak to them the better you're at it. You start saying, 'Ah yes, this is where the laser comes out. Of course, it has to be tuned into the transition I want to make, and here's the cell and here's the detector' which are all black boxes. [emphasis added]

Impeded from carrying out the fact-checking in person, theoreticians must resort to 'faith' or 'trust' in either the 'obviousness' of experimental trustworthiness, or trust in the job carried out by unknown colleagues who have bothered to go and 
check the facts (e.g. the ones who work full-time at LHC). Experimental results may then be trusted as second or even third-hand accounts because of the certainty, provided the larger world of institutionalized physics. A senior theoretician working on QCD simulations described the work of a colleague who works within a multi-site collaboration:

We had a meeting this weekend, and $M$ next door has gone to Durham, and he's taking some of our preliminary results up there, and he will discuss them with the experimenters. They will go away, and then of course they can e-mail back. You can then set up a dialogue where they don't quite understand exactly what we did, you see. We don't understand what they want to do. So you have to understand their physics. They're sceptical sometimes, and we're sometimes sceptical because you think, 'You didn't do this. You didn't do that. How does this work? I don't understand that.'

Theoreticians often used metaphors like 'networks' or (more often) 'chains' of physicists to refer to the channels for the dispersion of knowledge from experiment to high theory. Theoreticians are aware that experimental facts 'travel' from the lab to a theoretical setting not via single scientists, but rather via large numbers of individuals and knowledge webs that form intermediary links within the physics ecosystem, a large subset of which are not part of the high-theoreticians' own local network. One theoretician, also working on high-profile high-theoretical topics, described physics as a continuum of experts in which high-theoretical physics represented one end and experiment the other, with intermediate actors overlapping each other's physics between the endpoints:

The whole thing is this continuum where there are hard-core theoreticians at one end who only work on string theory, all the way through to the guy with the spanner, tightening up the nuts and bolts. There are thankfully big overlaps between each section, but yeah, I've never chatted to the guy with the spanner.

The need for overlaps and complex chains of knowledge between all elements of the physics 'continuum' was stressed by quoting a well known piece of physics lore, explaining how in contemporary physics it is now impossible for a single person to cover the entire spectrum 'from theory to spanner':

It's usually said that Fermi was the last guy to do [experimental work and theory simultaneously]. ${ }^{7}$ I don't know if that's a true statement. Certainly I don't know people that do it. I know of very impressive people that work on string theory - the geometry of extra dimensions - and at the same time do nuts and bolts work of top quark analysis from the data from LHC so they get their hands on the raw data and try to sift through and understand what's top quarks and what's not. That guy is a fairly extreme example because it seems that - to me at least - his two bits of work don't overlap. But to go all the way through, I don't think so. 
Yet even data-analyst cultures - made up of physicists who statistically analyze 'raw' data from experimental runs - are often also characterized by minimal contact with experimental cultures. A telling example is found in the Laser Interferometer Gravitational Wave Observatory (LIGO) collaboration; LIGO is subdivided into four major groups of researchers: the on-site experimenters, the data analysis team that works with the raw data, the 'theoretical' data analysts who work with the mathematics behind the actual data processing, and the 'future technology' team. ${ }^{8}$ A senior LIGO member, leader of one of the data-analysis teams, described during an interview the last two groups as being the most far removed from experiment itself, with the raw data analysts having the closest contact with experimenters and working with the data-readings directly produced by the on-site team. Nevertheless, he also described how his data analysis group has little direct contact with the experimental on-site team itself, so that even when problems come up with the data to be analysed, he does not feel enough rapport to call the on-site experimental team directly:

$R G$ : How does the actual communication go about? Do you ever call up the experimenters at the site? I was curious as to whether you just picked up the phone and...

Data analyst: Some people do. I don't know the guys at the site well enough to just pick up the phone and say, 'this is killing us', but I know the person I would talk to who is my expert and there's a chain... I don't know how it would get to them!

The 'expert' in this case turned out to be a graduate student who was sent to the experimental site for an extended period specifically to interact with the experimental team and be enculturated into the experimental team. The prolonged on-site exposure time was calculated so that the student could eventually have 'a foot in each camp' and would thus be able to 'translate' for the data analysis team what the experimental group said:

You need a few people with a foot in each camp who can almost translate, but there are a lot of people who just don't care to make that effort. I've done a bit, but you know one of my PhD students went to the site for four months and this was great for us because he came back and we'd hear something about what the detector did. And he's been there and helped work on it and he'd say, 'yeah, that means this'.

In contrast to the trading zone or the boundary object models of two-directional information flow, the existence of 'ambassadors' and 'translators' of data requires only unidirectional flow, such that the ambassador becomes a linguistic 'apprentice' to the target culture. It is therefore not necessary to set up an intermediary linguistic or conceptual common zone of interaction, so long as there is at least one trusted individual who can be a direct linguistic link to the experimental production site (in none of the above cases was it necessary for the on-site link to be able to be proficient in the experimental tasks). ${ }^{9}$ Once these 
'ambassadors' comes to grips with the language of the on-site data producers, the information is then amenable to transmission to the rest of the team in their own, translated, practice language. The data analyst team leader thus remarked:

We have our weekly meeting about what we analysed the last week by telecom. We'd get our story together and try to poke in on this data. Sometimes we will come to them. If my student was at the site he'd just come and pass it on. [...] To do something like that you need a point-topoint contact between the two groups, and that can be someone who's visiting somewhere, or it could just be a relationship that's grown up.

\section{Other conceptual and technical barriers to communication}

The barriers between high-theory and experiment aren't only due to differences in technical or linguistic aspects but can reach to even the more fundamental levels of how a problem is conceptualized. Although a full analysis of this is beyond the scope of this paper, a few observations are in order. One of the interviewees, who described himself as being halfway between the world of high-theory and applied mathematics, interestingly explained how experimenters also tend to find what is relevant about a physical system very different to what a high-theoretician would consider important:

$R G$ : Do you find it easy to communicate with experimental physicists?

Theoretician: No, no I don't. The reason is that they use different notations and different wave languages. It's irritating because sometimes you know from theory that a certain combination of variables is a parameter, one parameter, which is very useful. They use all the different constituent parameters. They keep eleven, or three of them, together and they often miss the point. [...]

He then added,

They don't think geometrically. Interesting, you think they might but they don't. Often it's very helpful to do so. They tend to think arithmetically, which is irritating. [...] There's a tendency in that direction which is very frustrating if you want to follow an argument.

Another young theoretician who works closely with experimenters within a quantum optics lab setting pointed out how the differences in time and material constraints also require one to adapt to different work cultures:

On one hand there's teamwork, and having to rely on other people. On the other hand, adapting yourself ... it can happen when you're working in [a] theoretical problem that you have a clear idea of where you want to go, that you begin down a road and it wasn't the correct one and you have to take another one. You also need a plan B there. As far as methodology goes you probably find fewer surprises. ... In general, to understand things 
[theoreticians] try to simplify things as much as possible. We try to cleanse the problem of all the collateral situations, and leave it as clean as possible. In experiment sometimes it is impossible to perform such isolation.

Pickering (1999) has discussed how, apart from disparities in techniques and jargon, dissimilar ontologies also populate subcultures' perspectives on a physical system. Galison has described how in early QCD physics dissimilar ontological perspectives differentiated the theoretical from the experimental communities; according to Galison (1997: 652), the language of experimenters was that of 'bubble chamber physics: lambdas, pions, kaons, protons, and sigmas embedded in the dynamics that describe their production and transformation' while the language of 'basic theory' (high-theory) was that of 'quarks, gluons and their interactions'.

\section{Varieties of trust}

As shown in the previous sections, the gaps in conceptual, methodological, technical, interpretative and linguistic elements 'force' theoreticians to trust or have faith in personally unverified experimental knowledge, but that this trust is bolstered by colleagues who form indirect links to experimental cultures. Trust can therefore take on a variety of forms: the direct appreciation of a colleague's skills or a well-earned reputation for good work; a theoretician-ambassador's passive acceptance of an experimental form of life which is initially like an alien culture; or, in more extreme cases where the expertise links become obscured by social distance, simply 'blind faith' in a standard experimental result.

Although in everyday usage these different types of trust are seldom differentiated, once examined in detail one can see very different mechanisms at work. Yet this differentiation is not often made in the scholarly literature, either, or is only mentioned in passing. In their general review of the trust literature, Mayer et al. (1995) found that it suffers from 'problems with the definition of trust itself; lack of clarity in the relationship between risk and trust; confusion between trust and its antecedents and outcomes; lack of specificity of trust referents leading to confusion in levels of analysis; and a failure to consider both the trusting party and the party to be trusted In this same spirit.' Hardin (2002: 5556) also has a poignant analysis on the uses and abuses of 'trust' as an explanatory catchphrase, particularly in the social sciences, concluding that the incomplete analyses of trust that are common in the literature 'are often, though not always, conceptually confused' and that 'casual accounts might not even distinguish trust in another person, trust in a fact of nature, and trust in an institution.'

I similarly propose a better understanding of communication and knowledge transfer in science, by looking specifically at the types of 'trust' that actually come into play in specific communication settings in order to understand how relationships between the groups of individuals in question shape their knowledge practices. My analysis is therefore also an attempt to overcome conceptual confusions on the different vernacular usages of 'trust' in STS, the intermixing of concepts as loose and diverse as trust, trustworthiness, confidence, credibility, risk, certainty, etc. 
The paper is not meant as a review of trust in STS as a whole, but rather a starting point for refocusing future discussions on trust in relation to knowledge transfer. I will specifically concentrate the rest of my discussion on how the empirical evidence collected above points to a relationship between social distance and different trust-based mechanisms.

\section{Trust and social distance}

Issues on trust have a long pedigree within STS. As Shapin (1995) notes, issues of how validity, credibility, trustworthiness and trust arise in scientists and their accounts are tied to the very roots of STS, and the differentiation between validity and credibility is the birthmark of the field as an autonomous discipline. Shapin also noted the need to elucidate not only 'classes of credibility predicaments', but also 'the tactics of credibility-management that seem pervasively pertinent to those classes' (p. 258). This is the task to be carried out here in relation to the following predicament: at ever increasing social distances from experiment, how is it that theoretical physicists can claim their practice to be 'empirically sound'? The answer, following Shapin, will lie in examining the types of 'trust'-based tactics on which I have shown theoreticians to rely.

The most immediate 'trust' that has been illustrated here, trust in a familiar and reputable scientific colleague, is known as either 'inter-personal trust' or 'foundational trust' in the sociological literature. Inter-personal trust will not be discussed in detail here, having been analysed in depth in many other STS contexts (Collins, 2001; Hedgecoe, 2012; Lewis and Atkinson, 2011; MacKenzie, 1990, 2001; Shapin, 1994; Stephens et al., 2011) and in the general sociology literature (Hardin, 2002, 2006; Mayer et al., 1995; Sztompka, 1999; Uslaner, 2002,) in how it relates to wider 'systemic trust' (e.g. Giddens, 1990, 1991; Luhmann, 1979; McDonell, 1997; Sztompka, 1999). Interpersonal and foundational trust, given that it is characterized by close inter-subjective bonds, constant contact between social actors and direct interactions, is the domain of least social distance; individuals that partake in developing this kind of trust maintain a good degree of interactions in common social settings.

As the distance between a high-theoretician and an experimental culture increases, another form of trust arises, a 'trust-by-proxy' that someone else has carried out the verification of knowledge or understood how an experimental result can be used in theorizing. In the 'ambassadorial' LIGO account, the proxy is himself linked to the group and the experimental culture directly by interpersonal trust bonds: the graduate student's account and interactional skills have to be taken at face value by the theoretical research group, just as the graduate student must take at face value the experimental culture. But in other cases, such as the QCD collaboration, the trust bonds may be partially established by the institutionally sanctioned position of a person, and not necessarily on personal acquaintance. ${ }^{10}$ Likewise, the young theoretician who sees the intermediary links in the spanner-to-theory chain disappear nevertheless 'trusts' that 'someone' has done the verification of experimental claims directly since he 'knows' that he could do it himself. 
This transition from 'visible' to 'partially visible' to 'invisible' proxies is quick as the social distance is increased. For example, in explaining the dynamics behind disseminating his own work in quark computer simulations, the senior QCD theoretician explained:

You publish the paper. The paper goes out. The title obviously attracts other people. They might be the experimenters directly who have their own pet theorists, but it might be other people who have a parameterization for the decay rate which takes into account things we can't calculate but in the middle sits this number we can calculate. I mean, I can't tell you their names. I can think of people that might do that. It's important to just seed the world with this knowledge in chunks, and it gets picked out. ${ }^{11}$ [emphasis added]

The collaborations he refers to here were set up directly by some of his colleagues as in the LIGO ambassador's case, but despite experimenters' work being fundamental to the project as a whole he himself had little personal contact with the experimenters. Morgan (2001) and Haycock (2011) have referred to actors who accompany 'facts' in their journey from their place of origin to the place where they will be used once these are prepared for 'travel' as chaperones. High-theoreticians have nearby colleagues who begin the 'chain of chaperones' that connect hightheory with experiment, but that become rapidly obscure as social distance increases. Despite no interpersonal trust coming into play, the distant chaperones that lie beyond the theoretician's local social event horizon must be hypothesised to be just as trustworthy as the closer ones if the knowledge they produce is to be taken as a trustworthy 'fact' and if the knowledge chain is to remain unbroken. There is, however, a source of confidence in this trust: acquaintance with the institutional world of physics and the structure of the profession as a whole. This socialization is what justifiably separates it from absolute 'blind faith'.

Intrinsically tied to but different to this type of direct socialization is what Collins and Evans (2007) have referred to as 'meta-expertises': skills, technical knowledge and particularly social knowledge that allows individuals to make sense of other cultures through acquaintance with one's own, so that 'those with little scientific knowledge can sometimes make what amounts to a technical judgment on the basis of their social understanding' (p. 45). There is a limit, however, to the effectiveness of meta-expertises that is tied to the proximity of these cultures. It would likely be possible for, say, a chemist or a mathematician to make sense of the social world of physics and to make sense of its most standardized technical parts. In fact, academics, university managers and research project directors often rely on similar 'referred social knowledge' to coordinate activities with individuals from dissimilar knowledge cultures based on knowledge of their own traditions, or of society at large (see for example Collins and Sanders 2007). Nevertheless, the power of meta-expertises decreases as the knowledge cultures become dissimilar, that is, increase in social distance. An STS scholar could likely make sense of a 'hard' scientific culture quite well even while being a social scientist, but we also know that many social scientists unacquainted with the natural sciences fail to do so and vice versa with natural scientists making sense of the social sciences. Giddens (1991) has discussed such cases of 'referred trust' noting that one can rely on the 
actions of sanctioned professionals (e.g. masons and architects) not because of a personal acquaintance with particular persons one interacts with sporadically, or with their social milieus, but because one is confident that their social worlds are close enough to our own that we can understand the trustworthiness of the institutions that sanction their roles (e.g. professional affiliations and accreditations).

Finally, we must consider the delegation of epistemic authority and depersonalization that distancing implies. The further a chaperone is from a hightheoretician, the less likely it is that the high-theoretician will have the necessary credentials to challenge the chaperone's authority, particularly between the furthest ends of the theory-to-spanner spectrum. ${ }^{12}$ Given enough social distance, the chaperones themselves can become completely obscure to the endpoints of the chain. The change from partial to full obscurity implies a final change in the social mechanisms that give rise to 'trust': a transition into the suspension of doubt, which is as close as one can come in science to actual 'blind faith'..$^{13}$ In both social and epistemic terms the suspension of doubt lies within the domain of largest social distance as all social interactions, direct or by proxy, disappear between the endpoints of emitter and receiver of knowledge. The suspension of doubt is the sociological mechanism that allows knowledge to flow across the largest social distances. This kind of knowledge transmission is particularly important in classic STS work such as Latour's (1986, 1987) and Latour and Woolgar's (1979) ethnographic studies of 'black boxed' laboratories: empirical knowledge factories whose end product $s$ are 'inscriptions'. As Robson (1992) points out when reconstructing the concept, 'the utilization of inscriptions [...] assists in enabling action at a distance.'

\section{A bundle of trust: Virtual empiricism}

I have argued that different degrees of social distance lead to different kinds of 'trust' and to different types of trust that fundamentally underlie communication in physics. Though some authors choose to identify 'trust' solely with interpersonal dimensions (e.g. Hardin, 2002; Shrum et al., 2001), many others do not make the distinction. The multiple vernacular uses of trust to some degree justify this practice, and there is no reason why we should deny this 'family resemblance' usage. Nevertheless, as has been argued, it is undeniable that what counts as 'trust' comes in distinct varieties. The three types of trust discussed above and their correlation to social distance are summarized in the following table: 


\begin{tabular}{|l|l|l|}
\hline Social distance & $\begin{array}{l}\text { Dominant type of } \\
\text { trust }\end{array}$ & $\begin{array}{l}\text { Characteristic type of knowledge } \\
\text { exchanged }\end{array}$ \\
\hline Minimal & $\begin{array}{l}\text { Foundational/ } \\
\text { Interpersonal trust }\end{array}$ & $\begin{array}{l}\text { Collective, relational and somatic } \\
\text { tacit/high level explicit technical } \\
\text { skills }\end{array}$ \\
\hline Medium & $\begin{array}{l}\text { Trust by } \\
\text { proxy/Institutional } \\
\text { trust }\end{array}$ & $\begin{array}{l}\text { Relational tacit knowledge/explicit } \\
\text { technical references /meta- } \\
\text { expertises and referred social } \\
\text { judgement }\end{array}$ \\
\hline Maximal & Suspension of doubt & Only explicit, inscription-type \\
\hline
\end{tabular}

Table 2: Relation between trust, social distance and type of knowledge that can be exchanged. The labels marking the amount of social distance are heuristic names. The classification of tacit knowledge is taken from Collins (2010) and can be linked to work by Collins \& Evans' (2007) in their 'Periodic Table of Expertise': at minimal distance, one can become fully socialized into a linguistic expert culture ('interactional expertise') while at medium distances any type of 'ubiquitous tacit knowledge' can be gained - possibly along with bits and pieces of the collective tacit knowledge of a knowledge culture. At maximal distances only inscriptions ('beer-mat knowledge' for Collins and Evans) can be acquired.

The important point here is that there is a qualitative jump between the observed mechanisms at work between the trust that supports knowledge flow as social distance increases. Additionally, the increase in social distance also imply limitations on the type of knowledge that can be meaningfully exchanged (Collins and Evans, 2007; Collins, 2010).

I will call the rhetorical intermixing of this set of trust-based strategies to deal with communication across social gaps virtual empiricism. 'Virtual empiricism' is $a b$ initio an actor's category necessary for the analyst to make sense of how physics 'really is' an empirical science in spite of the deep, cultural fragmentation between theory and experiment. Nevertheless, physics' virtual empiricism is not empty rhetoric - it is built up from tacit knowledge exchanges, socially embedded practices and acquaintance with the institutions of science, which allow theoreticians to justifiably (in a sociological sense) claim their work to be 'empirically sound'.

Virtual empiricism resonates, but also has significant differences, with Shapin and Schaffer's (1985) similarly termed concept of virtual witnessing. Virtual witnessing, the establishment of trust in experimental procedures outside the circle of those directly involved in material witnessing, is illustrated by Shapin and Schaffer (1985: 65) in Robert Boyle's usage of literary and rhetorical devices to multiply the number of 'witnesses' of particular experiments. In their account, Boyle tried to convince non-witnesses that his experiments were the trustworthy and accurate descriptions of careful experimental work by 'gentlemen scientists', by using naturalistic graphic portrayals and prolix descriptions of experiments. ${ }^{14}$ Later on, this was translated into the institutional framework of the Royal Society.

The salient difference between virtual empiricism and virtual witnessing is methodological - virtual witnessing focuses on historical processes of 
institutionalization of scientific knowledge, while virtual empiricism takes trust as an established pre-requisite for the communication of knowledge once it has been standardized. In this respect, virtual empiricism notes that institutionalization, while it may be seen as the end result of knowledge, cannot be sustained solely through institutionalization. The work of ambassadors, proxies and chaperones, the constant and sustained flow of knowledge, is just as important - no more, no less - as that of institutions in everyday science.

\section{Reassessing trust in STS using virtual empiricism: Two cases}

The theoretical complexity added by virtual empiricism relative to the straightforward 'trust'-based accounts criticised by Mayer and Hardin can only be justified if it adds further explanatory power. In this last section I will briefly reassess two important STS studies that problematize issues of trust, and note how reassessing their findings using virtual empiricism can add a richer explanation of them.

As a first example, MacKenzie (1990, 2001) has shown that amongst technology users and producer one can see the existence of a 'certainty trough', a phenomenon in which different levels of certainty or trust arise depending on users' social distance to the site of production. Apparently contradicting the thesis that 'trust' is fundamental to technology and knowledge transfer, MacKenzie finds that uncertainty/trust levels fluctuate in a typical manner - rising/dipping at the extremes of the distance scale, but being low/high in the middle areas. As is done here, MacKenzie also identifies three major social distance scales of knowledge exchange:

1) Individuals close to the locus of technology production have higher levels of uncertainty regarding the technology because they know the limitations that only insiders (those socialized into the technology production culture) can grasp in detail; this implies minimal levels of 'trust'.

2) Users institutionally committed to a technology display the largest amount of certainty and trust in the technology.

3) Non-users (users of a competing technology, for example) display the largest amounts of uncertainty, and least amounts of trust.

The apparent paradox that creators much better informed about a technology display significantly less trust that users who are further away is dissolved if, rather than looking at how an unspecified, monolithic type of 'trust' changes across social distance, one focuses on the type of trust that is predominant in each situation; the trough then would seem either to disappear or smooth out since:

1) Experts within or socialized into the locus of production must display high levels of foundational and interpersonal trust if they are to be part of a community at all, but then may be highly sceptical of accounts that try to institutionally legitimize a technology or that try to hide away the intrinsic uncertainties of technology (Collins, 1985). At this distance, minimal distance 
trust strategies are necessarily high, even though institutional or proxy-based trust is minimal.

2) As distance from the locus of production increases, MacKenzie finds that institutionalization standardizes the usage of technology alongside an increase in the delegation of epistemic authority to 'experts' in order to minimize uncertainty, a phenomenon well known to the STS literature (Star, 1985; Lahsen, 2005). Thus in mid-range settings institutional trust is high, even if there is no deep acquaintance through socialization of the core culture of a field of expertise.

3) At the extreme ends, non-users may of course have no acquaintance or trust in any form, or they may be absolutely passive recipients or users of the technology or knowledge. In the latter case, we are still within the realm of virtual empiricism, specifically where the suspension of doubt operates. Although interpersonal and even institutional trust is absent, 'trust' in abstract systems, meta-expertises and referred social knowledge, or suspension of doubt allows passive users to operate with the given technology, even if they hold nothing beyond operational knowledge of the technology.

We should keep in mind that social distancing is a twofold process that at the far extreme involves the suspension of doubt as well as the relegation of epistemic authority to 'experts' and their 'standardized' opinion. The case may then arise in which individuals don't use a piece of technology at all, or in which they reject knowledge claims not because of acquaintance with them, but because of complete separation from the social world of their source. In that case, experts/knowledge producers and the group of 'non-users' will live in completely dissimilar or antagonistic social worlds, even though the experts may still be recognised as such. In the case of 'crank science', for example, many theoretical physicists have recorded how the former often attack the experts themselves as 'defenders of the orthodoxy'. The scenario then lies outside the realm of virtual empiricism and within the realm of complete mistrust, for, as Luhman (1979) argues, some type of familiarity between social actors is necessary if one is to talk about the possibility of any sort of trust relationship existing between them. Beyond virtual empiricism's border lies, for example, the abyss between 'experts' and 'laypeople' responsible for the lack of trust which has been identified one of the fundamental problems of contemporary STS scholarship (Collins and Evans, 2007; Irwin, 2006).

A final application of virtual empiricism can be made by examining the work on Big Science collaborations by Shrum et al. $(2001,2007)$. The study they develop strongly questions the importance of 'trust' in STS analyses, finding 'trust' irrelevant to perceived success in strongly collaborative scientific contexts. Their empirical analysis of a number of large scale collaborations leads to the claim that that 'the role of trust in Big Science has been greatly exaggerated', so that in collaborative contexts trust 'is not of any fundamental significance' (Shrum et al., 2001: 682). This contrasts with typical STS outlooks such as Knorr-Cetina's (1999), which claim trust as fundamental to collaboration.

Working from an informed outlook on trust, Shrum et al. identify two forms of it: 'encapsulated interest' trust, that is, trust relationships based on mutual, 
shared interests; and 'confidence', or 'an orientation towards institutions such as government or the media' (Shrum et al. 2001: 687). In fact, upon closer scrutiny, what Shrum et al. argue is that encapsulated interest trust (of the minimal social distance type) is irrelevant, but that institutional trust is necessary for conflict to be minimized. But Shrum et al. (p. 686) earlier point out that what they call 'foundational trust' 'is necessary for collaboration in general - within science and without' yet that in being ubiquitous to all social interactions 'it warrants no special attention.' Strangely enough, given that it is earlier a 'taken for granted' element of social interaction, Shrum et al.'s (2007: 151-194) empirical analysis actually probes, mainly, the relevance of interpersonal trust, while later slipping into a non-specific usage of 'trust' that forgets the initial differentiation made between the foundational trust, institutional trust and confidence. This leads them to the seemingly anti-climactic conclusion (when compared to their strongly dismissive statement about 'trust') that their empirical evidence 'pertains to variations in trust' (Shrum et al., 2007: 215), and that 'trust both is and is not important' (Shrum et al., 2001: 718).

Despite the confusion in terminology, the conclusion that minimal-distance trust is irrelevant in collaborative contexts is certainly a striking one, and Shrum et al.'s results are interesting to contrast with the LIGO account presented here. LIGO has also faced problems on how to deal institutionally with the distances between its various constituent cultures and has worked to create platforms of cooperation. Although, like Shrum et al., I've argued that institutional trust is predominant at certain distances, LIGO collaborators strongly pointed out that interpersonal trust is necessary to bolster overall successes. A top level LIGO manager commented, for example, on how an ongoing effort to create a new comprehensive collaboration programme involved considerable help from the data-analyst team leader that during the interviews had placed a lot of emphasis on the necessity of having point-to-point interpersonal contact:

Even within the theoretical area there might be difficulties amongst different levels to talk to, for example, numerical relativists about numerical simulations of black holes. That's one area where we had a lot of difficulty understanding their language and effort was put in. [F - the same dataanalyst who described the ambassador student] was one of the leaders in starting a group called NINJA which helped create a platform in exchanging ideas. Not just ideas! Also to set up a language, a common language between these two. It requires a lot of effort.

The NINJA group has decided to focus on very specific topics that are of common interest to all participating groups. ${ }^{15}$ Unsurprisingly, these topics have the characteristics of boundary objects with which all the collaboration's members can interact with directly ('the merger phase of binary black hole (BBH) coalescence'). According to the top-level manager's description, NINJA is an attempt to create 'a common language' for collaboration - that is, the platform has all the characteristics of an emerging, coordinated trading zone. LIGO is similar to the institutional settings analysed by Shrum et al's in which trust 'is and is not important'. It is important for the data-analyst to understand the glitches of 
experiment through the student socialised into the experimental site culture, and in turn these sparse but vital interpersonal links eases the way and allow other communication infrastructures to operate efficiently. Likewise the creation of boundary objects and trading zones is necessary within the larger collaborative structure, but these also rely on the interactional bridges that socialisation practices create.

Rather than arguing that some sort of generic 'trust' or any specific form of it is the critical component of scientific communication, virtual empiricism starts out from the observed relevance of all forms of trust in scientific communication in all real settings and for all theoretical models of interaction (e.g. enculturation, boundary objects and trading zones). However, it then does specify the expected trust-channel that ought to dominate depending on the social distance between interacting cultures, an issue that should be empirically accessible once a scale of social distance is defined. Then at least one 'trust' element of virtual empiricism will be present for communication to occur, and it will mould the type interaction that is established between interacting cultures.

Finally, returning to the problem of disunity, I have illustrated that while common-ground strategies may dominate scientific communication in particular settings, enculturation practices have a similarly important place in sustaining communication at closer social distances. Enculturation relies on inter-personal trust, while common ground strategies depend on trust at intermediate and large distances - the virtual empiricist expanded version of trust bridges social distance gaps which knowledge must flow across whichever ones of these mechanisms are finally put into place.

Many issues on trust remain to be explored. The reverse communication flow of that analysed here - the communication of theoretical knowledge to experiment - has not been dealt with and certainly can make for an interesting follow up to this study. It is expected that the flow of theoretical knowledge to other subcultures would be of a similar nature and initial studies into the connection between high-theory and other subcultures - e.g. the relationship between physical theory and pure and applied mathematics - supports this thesis (Reyes-Galindo, 2011).

One would also expect, being based on general sociological arguments, that the approach should be relevant not just to physics but to scientific communication in general, which would require further empirical investigation. Additionally, issues on the types of trust that may appear in science or technology are by no means exhausted by my analysis. There is ample room for discussions of trust in STS beyond the virtual empiricism domain: discussion of trust not only between individuals or even groups, but also extending 'trust' to such diverse areas as computerized systems (MacKenzie 2001), public institutionalized standards (Porter 1995) and even aesthetic practices in science (Carusi 2008). 
References

Bourdieu P (1975) The specificity of the scientific field and the social conditions of the progress of reason. Social Science Information 14(6): 19-47.

Campbell RA (2003) Preparing the next generation of scientists: The social process of managing students. Social Studies of Science 33(6): 897-927.

Clarke A and Star SL (2008) The social worlds framework: A theory/methods package. In: Hackett EJ, Amsterdamska O, Lynch M and Wajcman J (eds) The Handbook of Science and Technology Studies. Cambridge, MA: MIT Press: 113137.

Collins HM (1984) Researching spoonbending: Concepts and practise of participatory fieldwork. In: Bell C and Roberts H (eds) Social Researching: Politics, Problems, Practice. London: Routledge and Kegan Paul: 54-69.

Collins HM (1992) Changing Order: Replication and Induction in Scientific Practice. Chicago, IL: University of Chicago Press.

Collins HM (2001) Tacit knowledge, trust and the Q of sapphire. Social Studies of Science 31(1): 71-85.

Collins HM (2004) Gravity's Shadow: The Search for Gravitational Waves. Chicago, IL: University of Chicago Press.

Collins HM (2010) Tacit and Explicit Knowledge. Chicago, IL: University of Chicago Press.

Collins HM (2011a) Language and practice. Social Studies of Science 41(2): 271-300.

Collins HM (2011b) Gravity's Ghost: Scientific Discovery in the Twenty-first Century. Chicago, IL: University of Chicago Press.

Collins HM and Evans R (2002) The Third Wave of Science Studies: Studies of expertise and experience. Social Studies of Science 32(2): 235-296.

Collins HM and Evans R (2007) Rethinking Expertise. Chicago, IL: University of Chicago Press.

Collins HM, Evans R and Gorman M (2007) Trading zones and interactional Expertise. Studies in History and Philosophy of Science Part A 38(4): 657-666.

Collins HM and Sanders G (2007). They give you the keys and say 'drive it! 'Managers, referred expertise, and other expertises. Studies In History and Philosophy of Science Part A, 38(4), 621-641.

Duhem P (1996) Essays in the History and Philosophy of Science. Indianapolis, IN: Hackett Publishing Company.

Dupré J (1995) The Disorder of Things: Metaphysical Foundations of the Disunity of Science. Cambridge, MA: Harvard University Press.

Dyson F (2004) A meeting with Enrico Fermi. Nature 427: 297.

Feyerabend, P (1975). Against Method, 3rd ed. London: Verso.

Galison P (1996a) Computer simulations and the trading zone. In: Galison P and Stump D (eds) The Disunity of Science: Boundaries, Contexts, and Power. Palo Alto, CA: Stanford University Press: 118-157.

Galison P (1996b) Introduction. In: Galison P and Stump D (eds) The Disunity of Science: Boundaries, Contexts, and Power. Palo Alto, CA: Stanford University Press: 1-36. 
Galison P (1997) Image and Logic: A Material Culture of Microphysics. Chicago, IL: University of Chicago Press.

Galison P (2010) Trading with the Enemy. In: Gorman E (ed) Trading Zones and Interactional Expertise: Creating New Kinds of Collaboration. Cambridge, MA: The MIT Press.

Galison P and Stump D (eds) (1996) The Disunity of Science: Boundaries, Contexts, and Power. Palo Alto, CA: Stanford University Press

Giddens A (1990) The Consequences of Modernity. Palo Alto, CA: Stanford University Press.

Giddens A (1991) Modernity and Self-Identity. Palo Alto, CA: Stanford University Press.

Gooding D (1986) How do scientists reach agreement about novel observations?" Studies in History and Philosophy of Science, Part A 17(2): 205-230.

Gorman M (ed) (2010) Trading Zones and Interactional Expertise: Creating New Kinds of Collaboration. Cambridge, MA: The MIT Press.

Hardin R (2002). Trust and Trustworthiness. New York: Russell Sage Foundation Publications.

Hardin R (2006) Trust. Cambridge, UK: Polity Press.

Haycock D (2011) The facts of life and death: A case of exceptional longevity. In: Howlet $\mathrm{P}$ and Morgan MS (eds) How well do Facts Travel? The Dissemination of Reliable Knowledge. Cambridge, UK: Cambridge University Press, pp. 403428.

Hedgecoe A (2102) Trust and regulatory organizations: The role of local knowledge and facework in research ethics review. Social Studies of Science 42(2): 662683.

Howlet P and Morgan MS (eds) (2011) How well do Facts Travel? The Dissemination of Reliable Knowledge. Cambridge, UK: Cambridge University Press.

Irwin A (2006) The politics of talk: Coming to terms with the 'new' scientific governance. Social Studies of Science 36(2): 299-320.

Kennefick D (2000) Star crushing: Theoretical practice and the theoreticians' regress. Social Studies of Science 30(1): 5-40.

Kennefick D (2007) Traveling at the Speed of Thought: Einstein and the Quest for Gravitational Waves. Princeton, NJ: Princeton University Press.

Knorr-Cetina K (1999). Epistemic Cultures: How the Sciences Make Knowledge. Cambridge, MA: Harvard University Press.

Lahsen M (2005). Seductive simulations? Uncertainty distribution around climate models. Social Studies of Science 35(6): 895-922.

Latour B and Woolgar S (1979) Laboratory Life: The Construction of Scientific Facts. Princeton, NJ: Princeton University Press, 1986 ed.

Latour B (1986) Visualization and cognition: Thinking with eyes and hands. Knowledge and Society: Studies in the Sociology of Culture Past and Present 6: 1-40.

Latour B (1987) Science in Action. Cambridge, MA: Harvard University Press.

Lewis J and Atkinson P (2011) The surveillance of cellular scientists' practice. BioSocieties 6(4): 381-400.

Luhmann N (1979) Trust and Power: Two Works by Niklas Luhmann. Chichester, UK: John Wiley \& Sons. 
MacKenzie D (1990) Inventing Accuracy: A Historical Sociology of Nuclear Missile Guidance. Cambridge, MA: The MIT Press.

MacKenzie D (2001) Mechanizing Proof: Computing, Risk and Trust. Cambridge, MA: MIT Press.

Mayer RC, Davis JH and Schoorman FD (1995) An integrative model of organizational trust. The Academy of Management Review 20(3): 709-734.

McDonell G (1997) Scientific and everyday knowledge: Trust and the politics of environmental initiatives. Social Studies of Science 27(6): 819-863.

Medawar P (1969) Induction and Intuition in Scientific Thought. London: Methuen.

Merz M and Knorr-Cetina K (1997) Deconstruction in a 'thinking' science: Theoretical physicists at work. Social Studies of Science 27(1): 73-111.

Monteiro M and Keating E (2009). Managing misunderstandings: The role of language in interdisciplinary scientific collaboration. Science Communication 31(1): 6-28.

Morgan MS (2001) Travelling facts. In: Howlet P and Morgan MS (eds) How well do Facts Travel? The Dissemination of Reliable Knowledge. Cambridge, UK: Cambridge University Press, pp. 3-39.

Pickering (1981) Constraints on controversy: The case of the magnetic monopole. Social Studies of Science 11(1): 63-93.

Pickering A (1984) Against putting the phenomena first: The discovery of the weak neutral current. Studies in History and Philosophy of Science 15(2): 85-117.

Pickering A (1999) Constructing Quarks: A Sociological History of Particle Physics. Chicago, IL: University of Chicago Press.

Pinch TJ (1986) Confronting Nature: The Sociology of Solar-Neutrino Detection. Dordrecht, NL: D. Reidel Publishing Company.

Porter TM (1996) Trust in Numbers: The Pursuit of Objectivity in Science and Public Life. Princeton: Princeton University Press.

Reber AS (1993) Implicit Learning and Tacit Knowledge. Oxford: Oxford University Press.

Reyes-Galindo L (2011) The sociology of theoretical physics. PhD thesis, Cardiff University, UK.

Ribeiro R (2007b) The role of interactional expertise in interpreting: The case of technology transfer in the steel industry. Studies In History and Philosophy of Science Part A 38(4): 713-721.

Robson, K (1992) Accounting numbers as 'inscription': Action at a distance and the development of accounting. Accounting, Organizations and Society 17(7): 685-708.

Schütz A (1967) The Phenomenology of the Social World. Evanston, IL: Northwestern University Press.

Shapin S (1994) A Social History of Truth: Civility and Science in Seventeenth-Century England. Chicago, IL: University of Chicago Press.

Shapin S (1995) Cordelia's love: Credibility and the social studies of science. Perspectives on Science 3(3): 255-275.

Shrager J (2010) From wizards to trading zones: Crossing the chasm of computers in scientific collaboration. In: Gorman M (ed) Trading Zones and Interactional Expertise: Creating New Kinds of Collaboration. Cambridge, MA: The MIT Press. 
Shrum W, Chompalov I and Genuth J (2001) Trust, conflict and performance in scientific collaborations. Social Studies of science 31(5): 681-730.

Shrum W, Genuth J, Chompalov I (2007) Structures of Scientific Collaboration. Cambridge, MA: MIT Press.

Star SL (1985) Scientific work and uncertainty. Social Studies of Science 15(3), 391427.

Star SL and Griesemer J (1989) Institutional ecology, translations' and boundary objects: Amateurs and professionals in Berkeley's Museum of Vertebrate Zoology, 1907-39. Social Studies of Science 19(3): 387-420.

Stephens N, Atkinson P, Glasner P (2011) Documenting the doable and doing the documented: Bridging strategies at the UK Stem Cell Bank. Social Studies of Science 41(6): 791-813.

Sztompka P (1999) Trust: A Sociological Theory. Cambridge, UK: Cambridge University Press.

Uslaner EM (2002) The Moral Foundations of Trust. Cambridge, UK: Cambridge University Press.

Wilson G and Herndl CG (2007) Boundary objects as rhetorical exigence: Knowledge mapping and interdisciplinary cooperation at the Los Alamos National Laboratory. Journal of Business and Technical Communication 21(2): 129-154.

Zee A (1986) Fearful Symmetry: The Search for Beauty in Modern Physics. New York: Macmillan.

${ }^{1}$ See Collins (1985), Galison (1997), Knorr-Cetina (1999) and Feyerabend (1975) for the locality of practice. See Dupré (1995) and the works in Galison and Stump (1996) for specific discussions on the relationship between the locality of practice, language and metaphysics and the 'disunity thesis'.

${ }^{2}$ Merz and Knorr-Cetina (1997) use a typology of theoretical physics micro-cultures that divide its practice into 'mathematical', 'high-theoretical' and 'phenomenological'. Galison (1997) also spells out the difference between a 'theoretical' and a 'phenomenological' culture in non-experimental physics. Other classifications are of course possible; see Reyes-Galindo (2011) where a classification of theoretical physics into a more diverse range of 'epistemic cultures' is carried out in the spirit of Knorr-Cetina's work on the diversity of experimental 'styles'. For brevity's sake, I have ignored this more accurate classification, as well as Merz and Knorr-Cetina's well known theses on the diversity of micro-cultures existing within experiment as a whole, treating 'experiment' as a monumental whole.

${ }^{3}$ In general, biological 'theory' tends to be connected with experiment. Biologists seem comfortable with the supposition that even 'theoreticians' ought to have ample lab experience, an attitude rarely if ever seen in theoretical physics circles. 
Immunologist Medawar (1969: 57) wrote that 'most scientists cannot be classified as either experimentalists or theorists, because most of us are both', a statement that while plausible in biology is definitely not the case in physics. However, Shrager (2010) points out that in molecular biology there has been a shift towards a situation similar to physics, where data producers and data users are separated from each other, with computer scientists and statisticians acting as middle-men. One of the theoreticians interviewed for this project - a former theoretical biologist who had worked and co-authored papers with one of the most eminent molecular biologists of the twentieth century - commented:

I arrived at theoretical biology just when the great era of theoretical biology had ended... the structure of DNA, how proteins are structured ... the kind of informational picture of biology had just been completed. There followed an epoch where everyone was so impressed by the success of theoreticians in biology that they backed it long after it had produced anything worthwhile. I was brought into the field with a background in maths because they thought I'd have the skills to do some theoretical biology. I did experimental work, which quite rightfully you had to do too, but I was meant to be a sort of semi-theoretical biologist. And I consider it to be a bogus profession; nothing ever came out of it. When I say it's a bogus subject in biology I mean there is no theory [by itself]. I sort of left molecular biology, fair enough, when it was becoming sensible to be a theoretician of a different kind, mainly the kind who does computer science and tries to organize data.

${ }^{4}$ As Pickering (1999: 4) summarizes in relation to physicists' popular writing, they describe their field as one where 'experiment is seen as the supreme arbiter of theory'. But Pickering $(1981,1984)$ has also shown how, in contradiction to this public façade, 'no scientific claim at either the instrumental or phenomenal level is absolutely compelling'. See also Duhem (1996).

${ }^{5}$ See Collins $(1984,1985)$. Discussing the importance of tacit knowledge in particle detector technology transfer, Galison (1997: 54) points out that in the dissemination of detector technology '[t]here is no doubt that there were instruments and effects the replication of which required no movement of personnel and objects.' Nevertheless, these were exactly the instances in which 'scientist-to-scientist "craft exchanges" [did] not figure at all'.

${ }^{6}$ There is, however, an important $20^{\text {th }}$ century theoretical tradition that tends to downplays the role of experiment, which I refer to as the 'first principles' approach to physical theory. This tradition played a significant role in the discourse surrounding the search for Grand Unified Theory of physics late in the century, particularly in popular expositions of theoretical physics. In physics lore, Einstein is often portrayed as the father of the unification ideal, and his search for 'symmetry' 
and 'beauty' fills first-principle theory mythology. Zee (1986), for example, writes, 'my colleagues and I in fundamental physics are the descendants of Albert Einstein; we like to think that we too search for beauty. Some physics equations are so ugly that we cannot bear to look at them, let alone write them down', adding that 'when presented with two alternative equations purporting to describe Nature, we always choose the one that appeals to our aesthetic sense. [...] Such is the rallying cry of fundamental physics.' Zee juxtaposes the attitude of 'fundamental physics' with those of

phenomenological theories, constructed simply to 'explain' a given phenomenon. Theorists craft such theories to fit the data, and get out as much as they put in. They lead their phenomenological theories, rather than the other way around. Such theories may be of great practical importance, but typically they tell us little, if anything, about other phenomena, and I find them to be of no fundamental interest.

See Galison (1997: 643) for a discussion of this same situation within quantum chromodynamics.

${ }^{7}$ Fermi is often portrayed as the last of physics' 'Renaissance men', a polymath who could build a crucial experiment just as well as he could construct the theory to explain it; see Dyson (2004) and Galison (1997: 798).

${ }^{8}$ LIGO is a collaboration of over 800 scientists housed at numerous institutions around the world, with one central aim: to find theoretically predicted but as yet undetected gravitational waves. It is currently the largest project ever funded by the National Science Foundation. For a full history of LIGO see Collins (2004, 2011b).

${ }^{9}$ Collins (2011a: 287) has described ambassador-like scientists in LIGO as possessing 'specialist interactional expertise', to stress that they have only linguistic and no practical immersion in the domain that they translate from, illustrating how the existence of these 'interactional ambassadors' or 'special interactional experts' in the gravitational wave community. Collins and Ribeiro (2007) have used the 'interactional expertise model' to analyse similar cases that involve the training of 'linguistic ambassadors' and 'cultural translators' to mediate inter-group communications in collaborative techno-scientific contexts.

${ }^{10}$ See Giddens (1990, 1991), Luhmann (1979) and McDonell (1997) for theoretical analyses of institutional trust and how it is arises from interpersonal situations. See Shapin (1994) for a historical analysis of the emergence of inter-personal and its transition to institutional trust in early physical science (the depersonalisation of trust) as well and Hedgecoe's (2012) empirical analysis of UK Research Ethics Committees surrounding the intermixing of the interpersonal and institutional forms of trust in practical contexts. 
${ }^{11}$ As it turns out, when carrying out a citation analysis of this theoretician's publications after the interview, the author found that - unknown to either the interviewer or the interviewee - one of the articles the interviewer had co-authored in his period as a physics researcher had once been cited by the interviewee.

${ }^{12}$ In one of the few in depth case studies on theoretical physics work, Kennefick $(2000,2007)$ analysed a debate within a general relativity theoretical community in which computer simulationists lying outside the relativist 'core set' presented results that were at odds with the theoretical standard views. Kennefick has argued that the simulationists faced several disadvantages in trying to overcome the relativists' rejection of their result, including the lack of 'social capital' at their disposal and their ability to understand the 'evidential context' of their results as outsiders. Thus, social distance was associated with both their ability to meaningfully intervene in the controversy as well as in finding a position of epistemic legitimacy within the community where they sought for the results to be relevant. See also Pinch (1986).

${ }^{13}$ This take on the 'suspension of doubt' follows Schütz's (1932: 98) description of the 'natural attitude'. See McDonell (1997), Sztompka (1999: 13) and Bourdieu (1975: 23) for sociological analyses of the suspension of doubt.

${ }^{14}$ In relation to experimental knowledge, Gooding (1986: 219) has used cases in the history of physics to explain how once a novel phenomenon has reached a point of stabilization, experimenters construct rationalized reconstructions of the experimental phenomenon in order to 'articulate a concept implicit in exploratory practices [...] or enable a phenomenon to be realised and made accessible to many observers'. Gooding notes that rational reconstructions of experiments such as Faraday's or Davy's are the end results of processes of -reification of meaning, as they go through stages of 'construal', interpretation', 'definitive interpretation' and 'exemplars', so that as the 'phenomenon' stabilizes its recipients become increasingly passive to the received knowledge.

${ }^{15}$ The NINJA (Numerical INJection Analysis) project is described in the group's wiki as follows:

The goal of the NINJA project is to bring the numerical relativity and data analysis communities together to pursue projects of common interest in the areas of gravitational-wave detection, astrophysics and astronomy. 